\title{
Parenting Practices as Mediators of Child Physical Activity and Weight Status
}

\author{
Paul D. Loprinzi ${ }^{a} \quad$ Bradley J. Cardinal $^{b}$ Kristina L. Loprinzic, ${ }^{c}$ Hyo Lee \\ a Lansing School of Nursing and Health Sciences, Department of Exercise Science, \\ Bellarmine University, Louisville, KY, ${ }^{b}$ Program in Exercise and Sport Science, School of \\ Biological and Population Health Sciences, College of Public Health and Human Sciences, \\ Oregon State University, Corvallis, OR, ' Lansing School of Nursing and Health Sciences, \\ Bellarmine University, ${ }^{d}$ Norton Hospital, Women's Pavilion, Louisville, KY, USA, ${ }^{\text {e Department }}$ \\ of Sport and Health Sciences, Sangmyung University, Seoul, South Korea
}

\section{Key Words}

Family $\cdot$ Motivation $\cdot$ Obesity $\cdot$ Socialization

\begin{abstract}
Understanding the environmental factors that influence children's physical activity is an important prerequisite before effective physical activity interventions can be developed and implemented. Parenting is one environmental factor that has been empirically shown to positively influence children's physical activity. However, in order to promote physical activity in children, a better understanding of how parents influence children's physical activity behavior is required. Previously, Birch and Davison developed a model depicting parental factors hypothesized to influence child dietary behaviors. We extended this model by identifying parental factors hypothesized to promote physical activity in children. This review focuses on the mediational role that parenting practices and behaviors play in influencing child mediators of physical activity behavior, and, ultimately, weight status. Priorities for future research are discussed.

Copyright (c) 2012 S. Karger GmbH, Freiburg
\end{abstract}

\section{Introduction}

The prevalence of obesity among children in the European Union and other developed countries has increased dramatically over the past three decades. For example, in France obesity rates increased from 10 to14\% between 1992 and 1996, in Greece the rates rose by $7 \%$ from 1984 to 2000, in Spain they increased from 23\% to 35\% between 1985-1986 and

Paul D. Loprinzi, PhD

Department of Exercise Science

Lansing School of Nursing and Health Sciences, Bellarmine University

Louisville, KY 40205 (USA)

Tel. +1 502272 8008, E-Mail ploprinzi @ bellarmine.edu 
1995-1996, and in the UK they increased from 8\% to 20\% between 1984 and 1998 [1]. These trends are similar to the situation in the USA, where, in 1971-1974, the rates for 6- to 11year-old children were $6.5 \%$, whereas in $2003-2006$ they were $17.0 \%$; and among 12 - to 19 -year-olds, the prevalence increased from $5 \%$ to $17.6 \%$ during this same time span [2]. Preventing obesity during early childhood is important, as young obese children are at a significantly increased risk for adolescent obesity [3] and, over time, they are more likely than their non-obese peers to experience significant short- and long-term health problems such as hyperlipidemia, hypertension, insulin resistance, respiratory problems, orthopedic complications, and cancer [4-6]. Additionally, the adverse social consequences of childhood obesity may have long lasting effects on psychological well-being [7] and economic mobility [8]. Moreover, obese children are at an increased risk for adult obesity [9] and the various chronic conditions that affect these individuals [8]. The rising trend in obesity among schoolage youth represents a critical public health problem, with a clear need to intervene to reduce the trajectory of childhood obesity.

Physical activity is a critical factor in the prevention of obesity in children [10]. However, despite the importance of physical activity, studies using objective measures of physical activity show that children do not accumulate sufficient levels of moderate-to-vigorous physical activity (MVPA). Data from the 2003-2004 National Health and Nutrition Examination Survey indicate that only $42 \%$ of American children aged 6-11 years are meeting the current 60-min MVPA recommendation [11]. For those 12- to 19 years old, the prevalence rate was only $8 \%$. In addition to physical activity behavior, children are spending considerable time in sedentary behaviors. Marshall and colleagues [12] estimated the international prevalence of television viewing in children and adolescents from empirical studies published between 1997 and 2002. In the 35 studies reviewed, 34\% of children and adolescents watched more than $2 \mathrm{~h}$ of television per day. There were no gender differences between prevalence estimates for boys (34\%) and girls (30\%). Similarly, television prevalence estimates were statistically consistent across countries (i.e., European countries $=40 \%$, Asia $=$ $31 \%$, and USA $=30 \%$ ). Understanding interpersonal factors that influence children's physical activity is an important prerequisite before effective physical activity interventions can be developed and implemented [13]. Parenting is one key interpersonal factor that has been empirically shown to positively influence children's physical activity [14]. However, in order to promote physical activity in children, a better understanding of how parents influence children's physical activity behavior is required. Figure 1 presents a model delineating parental factors hypothesized to influence child health behaviors (i.e., physical activity and dietary behavior). The lower half of the figure is a model developed by Birch and Davison [15] depicting parental factors hypothesized to promote familial patterns of adiposity and childhood overweight. Given that this model only addresses one side of the energy balance equation (i.e., energy intake), the top half of the model depicts parental factors hypothesized to promote physical activity in children (i.e., 6- to 11-year-olds). Essentially, this paper integrates physical activity into their model (i.e., energy expenditure). This integration provides a conceptual framework delineating the mechanisms through which parents influence their child's weight status through favorable changes in physical activity and dietary behaviors. The physical activity part of the model extends the work of Eccles [16-18], Brustad [19, 20], and Loprinzi [21] by incorporating the influence of child and parent weight status into the model as well as by identifying additional orientations and practices that may ultimately influence child weight status. 


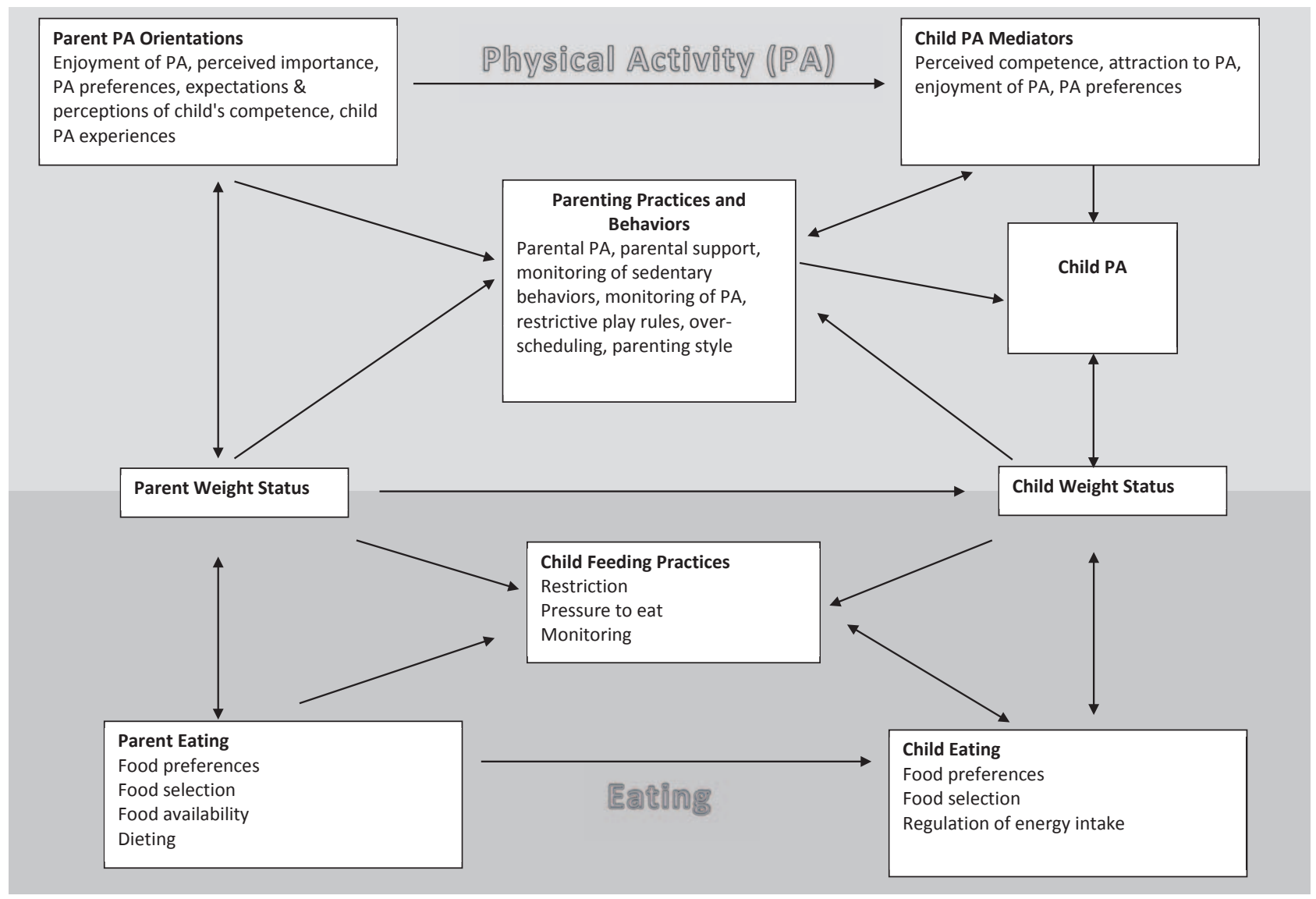

Fig. 1. Parental mediational factors hypothesized to influence child weight status.

\section{Overview of the Model}

As depicted in the top-half of the figure 1, parent physical activity orientations (e.g., perceived importance of physical activity) can directly influence child-level physical activity mediators (e.g., perceived competence and enjoyment of physical activity), which, in turn, can influence children's physical activity behavior. By definition, these mediating variables help to identify the mechanism by which parent physical activity orientations influence child physical activity. Parent physical activity orientations can also indirectly affect child physical activity behaviors and perceptions through its influence on different parenting practices and behaviors (e.g., parental support). For example, a parent who has a high level of perceived importance for child physical activity may provide more parental support for child physical activity, which, in turn, may positively influence children's regular participation in physical activity. Although direct genetic links between parent and child weight status are acknowledged in this model, the focus of this model revolves around the mediational role that parenting practices and behaviors play in influencing child mediators of physical activity and physical activity behavior and, ultimately, weight status.

Although the focus of this review is on parenting and its influence on child physical activity, we acknowledge that parents can positively influence their child's activity behavior by minimizing the amount of time spent in sedentary behaviors (e.g., watching TV, playing 
video games). Additionally, we acknowledge that other familial factors, such as siblings, may play an important role in shaping children's activity behavior. The overall goal of this review is not to provide an exhaustive quantitative review of the literature surrounding parental influences on child physical activity, but rather to overview the proposed model and examine research evidence assessing the link between the constructs.

\section{Parenting Practices and Behaviors $\rightarrow$ Child Physical Activity}

As shown in the core of the model diagram in figure 1, the parenting practices and behaviors that are hypothesized to influence child physical activity include: parental physical activity, parental support, monitoring of sedentary behavior, monitoring of physical activity behavior, employing restrictive play rules, over-scheduling, and parenting style. Importantly, we acknowledge that parenting style is not a parenting practice or behavior per se, but for the purpose of developing a parsimonious model parenting style was included in this group of parental influences. In fact, parenting style may act more as a moderator between activity-related parenting practices and child activity behavior and therefore influence the effectiveness of parenting practices; however, additional research to determine this is necessary. With respect to parental physical activity, it is hypothesized that parents' physical activity behavior may directly influence their child's physical activity behavior - a concept often referred to as parental modeling. Gustafson and Rhodes [14] reviewed the literature examining the influence of parent activity on child activity and showed that approximately half of the studies reported a positive association between parent and child physical activity [22-28], with the other half failing to observe such a relationship [29-34]. In support of the latter, Jago and colleagues [35] recently showed that among 3406 -year-old children from 40 schools in the UK, there was no association between objectively measured parent and child physical activity. Although there is some evidence that parental modeling of physical activity is important, studies [20,30] show that when parental support (e.g., providing encouragement, observing the child participate in physical activity, and facilitating physical activity opportunities) are considered along with the influence of parental physical activity, the effect of parental modeling appears to be less important. Expectedly, Gustafson and Rhodes [14], along with other studies [36, 37], showed that, overall, there is strong evidence linking parental support with child physical activity with nearly all of the reviewed studies demonstrating a positive association. Corroborating this, the more recent work of McMinn and colleagues [38] among 397 children in the European Youth Heart Study showed that parental instrumental support was significantly and positively associated with objectively measured child physical activity.

A possible parental influence for increasing children's physical activity behavior is parental monitoring of sedentary (i.e., monitoring the amount of time spent in screenbased activities) and activity behavior (e.g., keeping track of the amount of time the child spends outdoors). Providing some insight into the role of parental monitoring of sedentary behavior, Arredondo and colleagues [39] examined the relationship between parental monitoring of sedentary behavior, parental limit setting of sedentary behavior, and child physical activity. Among 812 Latino children (mean age $6.0 \pm 0.94$ years), parental monitoring of sedentary behavior was positively associated with child physical activity. Parental limit setting of sedentary behavior, however, was not related to children's physical activity behavior. With respect to monitoring child activity behavior, Taggart et al. [40] conducted a home-based activity program targeting parents. Parents were trained to monitor their child's physical activity levels by indicating on an activity data sheet when their child participated in physical activity based on set criteria. At the completion of the 12-week 
program, there was a $49 \%$ increase in the time children spent in physical activity, suggesting that parental monitoring of child physical activity is an effective strategy for increasing activity behavior in children.

Another potentially important, yet unstudied area of parenting is the effect of restrictive play rules (e.g., no running inside the house) on children's physical activity behavior. To date, only one study has explored this issue. In their cross-sectional study of 146 MexicanAmerican and Anglo-American preschool children, Sallis and colleagues [41] examined the effects of parental attempts to control children's physical activity through the enforcement of restrictive play rules. A significant inverse association between restrictive play rules and preschool physical activity levels was observed, suggesting that too many play rules can stifle young children's natural inclination to actively play.

A dimension of parenting that has been overlooked is the effect of over-scheduling on children's physical activity behavior. Hofferth and Sandberg [42] showed that, from 1981-1997, American children's free time declined by $12 \mathrm{~h} /$ week, playtime decreased by $3 \mathrm{~h} /$ week, and unstructured outdoor activities fell by 50\%. Providing a comparison between American and European children, Moore and Klass [43] empirically examined whether American children were busier or more overly scheduled compared to their European counterparts. Overall, among 85 American and 55 British families, no differences were observed. Although it is clear that children's lives are becoming more hectic, little research is available about whether these changes have negative outcomes such as reduced physical activity levels and increased risk of adiposity. Although we recognize that signing children up for sports and active games increases children's physical activity levels [44], scheduling children into too many structured or organized activities may, in theory, reduce children's free-play opportunities to engage in enjoyable, self-selected play activities. Research investigating this new area of inquiry is urgently needed. Additionally, the time commitment required for engaging children in multiple daily activities may make it difficult for parents to find the time to participate in regular physical activity. Although speculative, frequent parental support for physical activity (e.g., transporting and watching their child at sporting events) may have negative effects on the parents' physical activity levels. We recommend that future studies examine this upstream modeling (i.e., child activity influencing parent activity) hypothesis to determine if active children tend to have inactive parents because of the increased time commitment required to provide sufficient levels of instrumental support.

Although certain parenting practices (e.g., parental support) have been shown to be effective in promoting child physical activity, less research has investigated the influence that overall parenting style has on child physical activity. Parenting style is often determined based on scores of 'warmth' and 'control.' Authoritative parents exhibit high levels of warmth and control; authoritarian parents exhibit low warmth and high control; permissive parents exhibit high warmth and low control; and disengaged/uninvolved parents exhibit low warmth and control. Regarding dietary behaviors, it is commonly suggested that parents foster an authoritative feeding style [45]. Less evidence, however, has confirmed that this parenting style is ideal for promoting child physical activity. In light of this, Wake et al. [46] did show that authoritative parenting may help protect against preschool overweight and obesity. Similarly, young children (K-2 grade level) of parents who monitored and reinforced healthy behaviors (consistent with authoritative parenting) were more physically active compared to children of parents who did not employ these parenting practices [39]. Importantly, future studies testing this model should examine whether parenting style acts as a moderator or mediator of activity behavior, as in the academic domain and starting to be tested in the physical domain [47] parenting style has been shown to moderate the relationship between parental involvement and child academic success [48]. 
Overall, the research evidence demonstrates that parents can promote physical activity by providing optimal levels of support for physical activity, monitoring the amount of time their child engages in screen-based media, and keeping track of the amount of physical activity their child participates in. Before firm conclusions can be made about the other parenting practices, additional studies are needed.

\section{Parental Orientations $\rightarrow$ Parenting Practices $\rightarrow$ Child Physical Activity Mediators}

In addition to parenting practices and behaviors directly influencing child activity behavior, parental orientations, as depicted in the top-half of figure 1, are hypothesized to directly influence parenting practices and behaviors as well as child physical activity mediators. Unlike parenting practices and behaviors, parental orientations can be viewed as parents' beliefs, attitudes, or expectations toward physical activity. With regard to the theorization and link between parental orientations, parenting practices/behaviors, and childlevel mediators, the work of Eccles [16-18] and Brustad [19, 20] have been instrumental in this area.

Of the different parent physical activity orientations, the effects of parental enjoyment of physical activity, perceived importance of physical activity as well as expectations and perceptions of child physical competence on parenting practices and child activity mediators have received the most research attention. These links are supported by Eccles' [18] expectancy-value model, which hypothesizes that parents, who expect their child to be successful in a particular domain and value that domain, consequently provide more support to their child. In turn, the expectancies that parents communicate to their child can shape the child's own perceptions and expectations, thus ultimately influencing the child's behavior. Importantly, although parental orientations and practices strongly influences the child's own perceptions, expectations, and participatory involvement in physical activity, the frameworks of Eccles' model emphasize that it is the child's perception of the parent's beliefs, expectations, and attitudes that mediates this relationship.

To examine the influence of parental orientations on parenting practices and child mediators of physical activity, Brustad [19] tested a mediational model linking parental influences and children's self-perceptions with children's attraction to physical activity. 81 4th-grade children (39 boys and 42 girls, mean age $=10.4 \pm 0.3$ years) and their parents participated in the study. Participants were predominately Caucasian $(95 \%)$ with parents in the upper middle-class socioeconomic level. To assess parental orientations and practices, parental enjoyment of physical activity, parental importance of physical activity, and parental encouragement were measured. To assess child-mediating variables, child selfperceptions (perceived competence) and child's attraction to physical activity were measured. Child attraction to physical activity was determined through various dimensions, including attraction to vigorous exercise, liking of games/sports, importance of exercise, peer acceptance in games/sports, and fun of physical exertion. Results showed that parental orientations, namely parental enjoyment of physical activity, were associated with parental encouragement to be active. Notably, boys received more encouragement to be active than girls. Parental encouragement in turn was positively associated with the child's perceived competence, with child's perceived competence in turn positively associated with each dimension of child's attraction to physical activity/sports. Although this study did not directly assess the parents' perceptions regarding their child's physical competency, it did indirectly assess these beliefs as reflected by encouragement levels.

Similar to this study, Brustad [20] conducted a study examining the parental orientations and practices on the influence of the psychological dimensions of children's physical 
activity attraction. This study uniquely involved families of lower socioeconomic levels. Participants included 107 children (48 boys and 59 girls, mean age $=10.6 \pm 0.9$ years) in grades 4-6. Participants were predominately Latino (66\%) and Caucasian (32\%). Another big difference between the two Brustad studies $[19,20]$ was that the 1996 study examined the potential forms of parental orientations and practices through the perception of the child. That is, parental enjoyment of physical activity and parental encouragement of physical activity were assessed by the children themselves. This is a key element of Eccles' expectancy-value model as this model, as previously described, suggests that parental orientations and practices influence the child's self-perceptions through the child's perceptions of their parent's beliefs, expectations, and attitudes. The results showed that in boys, perceived parental encouragement and perceived parental enjoyment of physical activity were strongly associated with child's perceived competence, liking of games/sports, and fun of physical exertion. Similar results were found for girls; however, fun of physical exertion did not emerge as a significant variable, whereas peer acceptance in games and sports did.

Similar to these studies, Bois and colleagues [49] found that among 152 French children, mothers' beliefs about their child's competence had an indirect effect on children's physical activity by influencing children's perceived competence which, in turn, influenced the child's activity behavior. Collectively, these studies provide support for the proposed model that parental orientations influence child mediators of physical activity both directly and indirectly through parenting practices. In support of the work of Brustad [19, 20], several other studies have also demonstrated that parental orientations and practices are important in shaping child mediators of physical activity $[28,50]$. Given that parental orientations and practices are strong predictors of child self-perceptions in the physical domain, parents should provide physical activity-related support to their child regardless of the perceptions they have toward their child's physical ability.

\section{Parent and Child Weight Status}

As demonstrated in the model, parental weight status may play a role in shaping parental orientations and practices. Although the research evidence linking parent weight status to parent physical activity orientations is limited, logically overweight parents may have less favorable orientations, such as enjoyment of physical activity, given their lower physical activity levels than their non-overweight counterparts [51]. Similarly, there is a paucity of research examining the link between parent weight status and parenting practices. However, to better understand the relationship between parent weight status and parenting practices, Klesges et al. [52] examined the association between parental prompts for physical activity and parent's weight. In a sample of 30 preschool children, the results showed an inverse association between parental prompts for physical activity and parent weight, suggesting that parents with a higher relative weight are less likely to provide encouragement to their children to be active. These results suggest that one potentially effective strategy to increase physical activity among preschool children may be through reductions of parental adiposity through promotion of physical activity among parents. The results of a recent intervention study targeting women with young children suggest that increasing access to 'parent friendly' physical activity programs that offer child care or concurrent programming for children, providing information on how to overcome physical activity barriers that are specific to parents with young children, and negotiating for greater partner support for physical activity time are effective strategies to increase physical activity in parents with young children [53]. 
In addition to parent's own weight status, parenting practices may be influenced by the child's weight status. This domain-specific parenting was first introduced by Costanzo and Woody [54], arguing that parenting is influenced by the child's phenotype as well as the parent's concerns and perceptions of the child's risk for developing a particular problem, which in this case, is adiposity.

To date, the evidence is mixed with regard to whether parenting practices differ based on the child's weight. With respect to parental support, some studies have reported an inverse association between parental support and child relative weight [52,55,56], whereas others have reported no association [56-60]. With regard to parenting style, one study showed that compared with children of authoritative parents, the odds of a child being in a heavier BMI category increased by $59 \%$ for those children with permissive fathers and by $35 \%$ for those children with disengaged fathers [46]; however, when maternal parenting style was examined, no relationship emerged. Similarly to the null findings reported for mothers, a different study conducted by Gable and colleagues [61] showed that authoritative and authoritarian parenting styles were not significantly different between obese and nonobese children.

Given the few studies examining the relationship between parent weight status and parental orientations and practices, it is difficult to draw conclusions as to how parental weight status influences these constructs. With respect to child weight status, the available evidence suggests that parents are not differentially altering their parenting based on the phenotype of their child. Given the consistent positive association between parental support and child physical activity, it appears that all children, regardless of weight status, can benefit from sufficient levels of parental support for physical activity.

\section{Conclusion and Recommendations}

Parents play a strong role in shaping child physical activity behavior. Central to the proposed model of parental influence, parents can influence their child's physical activity behavior through multiple mechanisms. The research evidence shows that parental orientations, such as enjoyment of physical activity, importance of physical activity, expectation that their child will be successful in physical activity and a sense of value of success, influence specific parenting practices, such as parental support. This support can influence the competence perceptions of children which, in turn, can influence their physical activity behavior. Of note, the child's perceptions of their parent's beliefs are an important factor in the construction of their own competence perceptions. The reviewed studies provide support for the mediational influence of parenting practices and behaviors, thus emphasizing the need to intervene with parents if we want to increase the physical activity levels of children.

Because perceived physical competence $[62,63]$ as well as other child-level mediators of physical activity such as enjoyment of physical activity [64] are important influences on physical activity, efforts to increase such mediators by encouraging parents to provide opportunities for enjoyment of activities as well as providing support for their child's physical activities through observing, encouraging, participating, and facilitating opportunities to be active will be paramount in increasing physical activity levels among children. Specific examples in which parents can provide instrumental support for their child's physical activity include, but are not limited to, signing their child up for physical activity or sporting classes at recreation or community centers, taking their child to the park and actively engaging in physical activity or sport with their child, setting up active play dates with the child's peers, and teaching their child how to play active games/sports. Intervention 
efforts should aim to increase parental perceptions of their child's physical competence by educating parents that all children can be successful in participating in physical activity/ sport. Finally, in order to develop effective family-based interventions, a more complete knowledge base of how parental orientations and practices influence the mediators of activity behavior and physical activity levels of children are needed.

The model presented here provides an example of how researchers can investigate the direct and indirect effects of parenting on child activity behavior. Specifically, we need additional studies investigating understudied parental orientation variables, such as the parent's physical activity experiences as a child and how these experiences influence their parenting practices. Additionally, we need a better understanding of how parental weight status influences parenting practices and orientations as well as of the influence of parenting style on children's physical activity behavior. Finally, to provide a more detailed explanation as to how parents influence child physical activity, future research investigations should examine the potential moderating effect of gender, sociocultural, and socioeconomic influences.

\section{Disclosure Statement}

The authors declare no conflict of interest.

\section{References}

1 Dehghan M, Akhtar-Danesh N, Merchant AT: Childhood obesity, prevalence and prevention. Nutr J 2005;4: 24.

2 Ogden CL, Carroll MD, Flegal KM: High body mass index for age among US children and adolescents, 20032006. JAMA 2008;299:2401-2405.

- 3 Veltsista A, Kanaka C, Gika A, Lekea V, Roma E, Bakoula C: Tracking of overweight and obesity in Greek youth. Obes Facts 2010;3:166-172.

- 4 Freedman DS, Dietz WH, Srinivasan SR, Berenson GS: The relation of overweight to cardiovascular risk factors among children and adolescents: the Bogalusa Heart Study. Pediatrics 1999;103:1175-1182.

- 5 Fuemmeler BF, Pendzich MK, Tercyak KP: Weight, dietary behavior, and physical activity in childhood and adolescence: implications for adult cancer risk. Obes Facts 2009;2:179-186.

- 6 Craig LC, Love J, Ratcliffe B, McNeill G: Overweight and cardiovascular risk factors in 4- to 18-year-olds. Obes Facts 2008;1:237-242.

7 Dietz WH: Health consequences of obesity in youth: childhood predictors of adult disease. Pediatrics 1998; 101:518-525.

- 8 Must A, Spadano J, Coakley EH, Field AE, Colditz G, Dietz WH: The disease burden associated with overweight and obesity. JAMA 1999;282:1523-1529.

- 9 Telama R: Tracking of physical activity from childhood to adulthood: a review. Obes Facts 2009;2:187-195.

10 Plachta-Danielzik S, Landsberg B, Lange D, Seiberl J, Muller MJ: Eight-year follow-up of school-based intervention on childhood overweight - the Kiel Obesity Prevention Study. Obes Facts 2011;4:35-43.

11 Troiano RP, Berrigan D, Dodd KW, Masse LC, Tilert T, McDowell M: Physical activity in the United States measured by accelerometer. Med Sci Sports Exerc 2008;40:181-188.

12 Marshall SJ, Gorely T, Biddle SJ: A descriptive epidemiology of screen-based media use in youth: a review and critique. J Adolesc 2006;29:333-349.

13 Sallis JF, Owen N, Fotheringham MJ: Behavioral epidemiology: a systematic framework to classify phases of research on health promotion and disease prevention. Ann Behav Med 2000;22:294-298.

14 Gustafson SL, Rhodes RE: Parental correlates of physical activity in children and early adolescents. Sports Med 2006;36:79-97.

15 Birch LL, Davison KK: Family environmental factors influencing the developing behavioral controls of food intake and childhood overweight. Pediatr Clin North Am 2001;48:893-907.

16 Eccles J, Adler T, Futterman R, Goff S, Kaczala C, Meece J, Midgley C: Expectations, values and academic behaviors; in Spence JT (ed): Achievement and Achievement Motivation. San Francisco, W.H. Freeman, 1983, pp 75-146.

17 Eccles J, Wigfield A, Schiefele U: Motivation to succeed.; in Eisenberg N (ed): Handbook of Child Psychology: Vol 3 Social, Emotional and Personality Development, 5th ed. New York, Wiley, 1998, pp 1017-1094. 
Loprinzi et al.: Parenting Practices as Mediators of Child Physical Activity and Weight Status

18 Eccles JS, Harold R: Gender differences in sport involvement: applying the Eccles' Expectancy-Value Model. J Appl Sport Psychol 1991;3:7-35.

19 Brustad RJ: Who will go out and play? Parental and psychological influences on children's attraction to physical activity. Pediatr Exerc Sci 1993;5:210-223.

20 Brustad RJ: Attraction to physical activity in urban schoolchildren: parental socialization and gender influences. Res Q Exerc Sport 1996;67:316-323.

-21 Loprinzi PD, Trost SG: Parental influences on physical activity behavior in preschool children. Prev Med 2010;50:129-133.

22 Freedson PS, Evenson S: Familial aggregation in physical activity. Res Q Exerc Sport 1991;62:384-389.

-23 Moore LL, Lombardi DA, White MJ, Campbell JL, Oliveria SA, Ellison RC: Influence of parents' physical activity levels on activity levels of young children. J Pediatr 1991;118:215-219.

24 Gottlieb NH, Chen MS: Sociocultural correlates of childhood sporting activities: their implications for heart health. Soc Sci Med 1985;21:533-539.

-25 Sallis JF, Patterson TL, Buono MJ, Atkins CJ, Nader PR: Aggregation of physical activity habits in MexicanAmerican and Anglo families. J Behav Med 1988;11:31-41.

-26 Sallis JF, Patterson TL, McKenzie TL, Nader PR: Family variables and physical activity in preschool children. J Dev Behav Pediatr 1988;9:57-61.

27 Stucky-Ropp RC, DiLorenzo TM: Determinants of exercise in children. Prev Med 1993;22:880-889.

28 Welk GJ, Wood K, Morss G: Parental influences on physical activity in children: An exploration of potential mechanisms. Pediatr Exerc Sci 2003;15:19-33.

29 Sallis JF, Alcaraz JE, McKenzie TL, Hovell MF, Kolody B, Nader PR: Parental behavior in relation to physical activity and fitness in 9-year-old children. Am J Dis Child 1992;146:1383-1388.

-30 Dempsey JM, Kimiecik JC, Horn TS: Parental influence on children's moderate to vigorous physical activity participation: An expectancy-value approach. Pediatr Exerc Sci 1993;5:151-167.

-31 Aarnio M, Winter T, Kujala UM, Kaprio J: Familial aggregation of leisure-time physical activity - a three generation study. Int J Sports Med 1997;18:549-556.

-32 Kimiecik JC, Horn TS: Parental beliefs and children's moderate-to-vigorous physical activity. Res Q Exerc Sport 1998;69:163-175.

-33 Campbell PT, Katzmarzyk PT, Malina RM, Rao DC, Perusse L, Bouchard C: Prediction of physical activity and physical work capacity (PWC150) in young adulthood from childhood and adolescence with consideration of parental measures. Am J Hum Biol 2001;13:190-196.

-34 McGuire MT, Hannan PJ, Neumark-Sztainer D, Cossrow NH, Story M: Parental correlates of physical activity in a racially/ethnically diverse adolescent sample. J Adolesc Health 2002;30:253-261.

35 Jago R, Fox KR, Page AS, Brockman R, Thompson JL: Parent and child physical activity and sedentary time: do active parents foster active children? BMC Public Health 2010;10:194.

36 Beets MW, Vogel R, Forlaw L, Pitetti KH, Cardinal BJ: Social support and youth physical activity: the role of provider and type. Am J Health Behav 2006;30:278-289.

-37 Beets MW, Cardinal BJ, Alderman BL: Parental social support and the physical activity-related behaviors of youth: a review. Health Educ Behav 2010;37:621-644.

-38 McMinn AM, Van Sluijs EM, Wedderkopp N, Froberg K, Griffin SJ: Sociocultural correlates of physical activity in children and adolescents: findings from the Danish arm of the European Youth Heart Study. Pediatr Exerc Sci 2008;20:319-332.

-39 Arredondo EM, Elder JP, Ayala GX, Campbell N, Baquero B, Duerksen S: Is parenting style related to children's healthy eating and physical activity in Latino families? Health Educ Res 2006;21:862-871.

$\rightarrow 40$ Taggart AC, Taggart J, Siedentop D: Effects of a home-based activity program. A study with low fitness elementary school children. Behav Modif 1986;10:487-507.

-41 Sallis JF, Nader PR, Broyles SL, Berry CC, Elder JP, McKenzie TL, Nelson JA: Correlates of physical activity at home in Mexican-American and Anglo-American preschool children. Health Psychol 1993;12:390-398.

-42 Hofferth SL, Sandberg JF: How American children spend their time. J Marriage Family 2001;63:295-309.

43 Moore MK, Klass PH: Understanding parents' expectations and hurrying: United States and England. Early Child hood Education Curriculum and Instruction Department, Ilinois State Univer sity. Int J Early Child hood 1995;27:30-36.

44 Katzmarzyk PT, Malina RM: Contribution of organized sports participation to estimated daily energy expenditure in youth. Pediatr Exerc Sci 2000;10:378-385.

45 Rhee KE, Lumeng JC, Appugliese DP, Kaciroti N, Bradley RH: Parenting styles and overweight status in first grade. Pediatrics 2006; 117:2047-2054.

-46 Wake M, Nicholson JM, Hardy P, Smith K: Preschooler obesity and parenting styles of mothers and fathers: Australian national population study. Pediatrics 2007;120:e1520-1527.

47 Hennessy E, Hughes SO, Goldberg JP, Hyatt RR, Economos CD: Parent-child interactions and objectively measured child physical activity: a cross-sectional study. Int J Behav Nutr Phys Act 2010; 7:71.

48 Darling N, Steinberg, L. Parenting style as context: an integrative model. Psychol Bull 1993;113:487-496.

-49 Bois JE, Sarrazin PG, Brustad RJ, Trouilloud DO, Cury F: Elementary schoolchildren's perceived competence and physical and physical activity involvement: the influence of parents' role modeling behaviors and perceptions of their child's competence. J Sport Exerc Psychol 2005;6:381-397. 
50 Beets MW, Pitetti KH, Forlaw L: The role of self-efficacy and referent specific social support in promoting rural adolescent girls' physical activity. Am J Health Behav 2007;31:227-237.

51 Davis JN, Hodges VA, Gillham MB: Physical activity compliance: differences between overweight/obese and normal-weight adults. Obesity (Silver Spring) 2006;14:2259-2265.

52 Klesges RC, Malott JM, Boschee PF, Weber JM: The effects of parental influences on children's food intake, physical activity, and relative weight. Int J Eat Disord 1986;5:335-346.

53 Miller YD, Trost SG, Brown WJ: Mediators of physical activity behavior change among women with young children. Am J Prev Med 2002;23:98-103.

$\$ 54$ Costanzo PR, Woody EZ: Domain specific parenting styles and their impact on the child's development of particular deviance: the example of obesity proneness. J Clin Psychol 1985;3:425-445.

55 De Bourdeaudhuij I, Lefevre J, Deforche B, Wijndaele K, Matton L, Philippaerts R: Physical activity and psychosocial correlates in normal weight and overweight 11 to 19 year olds. Obes Res 2005;13:1097-1105.

56 Zabinski MF, Saelens BE, Stein RI, Hayden-Wade HA, Wilfley DE: Overweight children's barriers to and support for physical activity. Obes Res 2003;11:238-246.

57 Fulkerson JA, French SA, Story M: Weight-bearing physical activity among girls and mothers: relationships to girls' weight status. Obes Res 2004;12:258-266.

58 Klesges RC, Coates TJ, Moldenhauer-Klesges LM: The FATS: an observational system for assessing physical activity in children and associated parent behavior. Behav Assess 1984;6:333-345.

59 Taylor WC, Sallis JF, Dowda M: Activity patterns and correlates among youth: differences by weight status. Pediatr Exerc Sci 2002;14:418-431.

60 Springer AE, Kelder SH, Hoelscher DM: Social support, physical activity and sedentary behavior among 6th-grade girls: a cross-sectional study. Int J Behav Nutr Phys Act 2006;3:8.

61 Gable S, Lutz S: Household, parent, and child contributions to childhood obesity. Family Relations 2000;49: 293-300.

62 Bandura A: Social Foundations of Thought and Action: A Social Cognitive Theory. Englewood Cliffs, Prentice Hall, 1986.

63 Harter S: Effectance motivation reconsidered: toward a developmental model. Hum Dev 1978;21:34-64.

64 Dishman RK, Motl RW, Saunders R: Enjoyment mediates effects of a school-based physical activity intervention. Med Sci Sports Exerc 2005;37:478-487. 